\title{
Resilience of food, energy, and water systems to a sudden labor shortage
}

\author{
Ebrahim $\operatorname{Karan}^{1}[$ D Sadegh Asgari²
}

Accepted: 4 December 2020 / Published online: 4 January 2021

(c) The Author(s), under exclusive licence to Springer Science+Business Media, LLC part of Springer Nature 2021

\begin{abstract}
Past research studies have acknowledged the role of resilience in policies and decisions to address disruptive events and proposed frameworks to measure it. The scope and diversity of these unwanted events highlight the need to evaluate the resilience of a system to a specific disruptive circumstance. The broad scope and generic form of the previous studies limit their usefulness as a practical tool for analyzing the factors affecting system performance. To overcome this problem, we are only focusing on the behavior of systems that produce, distribute, and deliver food, energy, and water (FEW) during and after the occurrence of a sudden shortage of labor. Resilience metrics are first developed to measure the resilience of the FEW systems. Next, the performance levels of the FEW systems are clearly defined based on the FEW demands that are not served. Third, the labor intensity of FEW productions is calculated to assess the impact of a sudden labor shortage. This study recognizes the complex interdependencies among the FEW systems and, thus, aims to examine their resilience as a single system. Last, the labor shortage in the USA caused by the COVID-19 pandemic is chosen as a use case to measure the system performance and role of adjustments on the FEW systems. The results show that a labor shortage can significantly impact the FEW system performance, possibly due to the high energy dependency of food and water systems and the high cost of storing energy. Also, the current food system has shown more resilience to a sudden labor shortage compared to the energy and water systems because of the availability of various food alternatives to meet the demand for each food category.
\end{abstract}

Keywords Resilience $\cdot$ Food-energy-water $\cdot$ System performance $\cdot$ Labor shortage $\cdot$ Labor intensity

\section{Introduction}

As we are striving to maintain and improve the quality of services delivered by critical infrastructures systems during a pandemic, resilience becomes more and more important. Several researchers have provided valuable insights into the behavior of these systems during and after the occurrence of disruptive events (Govindan and Al-Ansari 2019; Schlör et al. 2018; Scott et al. 2015; Zimmerman et al. 2016). Despite their markedly different approaches, studies

Ebrahim Karan

Ebrahim.Karan@shsu.edu

Sadegh Asgari

asgaris@merrimack.edu

1 Department of Engineering Technology, Sam Houston State University, 1019 Bowers Boulevard, Huntsville, TX 77341, USA

2 Department of Civil Engineering, Merrimack College, 315 Turnpike Street, North Andover, MA 01845, USA on systems resilience emphasize the role of quantifying the resilience of the network of essential resources and/or services. Metrics are developed and used to measure and evaluate the behavior of systems such as time-dependent operational and infrastructure resilience metrics proposed by Panteli et al. (2017) or systemic resilience in terms of individual asset level and vulnerability characteristics of critical infrastructure networks by Pant et al. (2018).

The challenge of a labor shortage is not new, and many studies have investigated the vulnerability of a system to a labor shortage. This problem, however, has never really gained enough traction until recently when the new coronavirus began to spread. Labor-intensive industries (e.g.,, agriculture and food service) are facing a shortage of workers to produce, distribute, or deliver the products as the novel coronavirus pandemic intensifies. The need for increasing resilience of critical infrastructure systems during volatile health emergencies, such as the outbreak of coronavirus disease 2019 (COVID-19), is more important than ever in today's world. This will undoubtedly place increasing 
pressures on those responsible for providing us with fundamental needs such as food, energy, and water. To limit the spread of COVID-19, many workers have been ordered home or to self-quarantine and thus unable to work. Hynes et al. (2020) reviewed the impact of COVID-19 and discussed the notion of resilience on socioeconomic systems. They concluded that system analysis models have to improve to better integrate real-world dynamics such as social and behavioral heterogeneity. To evaluate the effectiveness of FEW policies and their systemic impacts, this study seeks to understand to what extent the resilience of food, energy, and water (FEW) systems enables us to successfully respond to unexpected labor shortage shocks.

To achieve this goal, we should first clarify the meaning of the term 'resilience' and provide the scopes and dimensions encompassed by it. Although previous studies differ substantially in their underlying assumptions and consequently in their modeling structure, they have two elements in common: the system performance and the disruptive event. The scope of the study is limited to the interlinkage between FEW systems and the effects of a particular disruptive event on the system's performance. The disruptive event is a sudden labor shortage. In the following sections, we will discuss in more detail how the resilience of FEW systems can be defined. Section 5 aims to describe and measure system performance. The scope of this study is limited to the behavior of FEW during and after the occurrence of a sudden shortage of labor. Thus, the labor intensity of FEW productions is measured in section 6. It is essential to know the amounts of labor used to produce FEW goods or services. The labor-related data (e.g., employment data) are available from multiple sources and/or on multiple variables. This study can contribute to the literature by compiling laborrelated data and presenting it in a summarized format. We focus on the workforce directly involved in the production and governance of FEW systems in the US to provide a dataset that can be used for the FEW system assessments. This is followed by the assessment of the impact of a sudden labor shortage on the resilience of FEW systems.

\section{Problem description}

Because of the diversity of the FEW systems and the wide disparities in their production rates, the resilience analysis frameworks developed or proposed over the past few years failed to obtain wide acceptance and practical use. The U.S. Department of Homeland Security managed and implemented over sixty projects and programs during the last decade to help strengthen the security and resilience of the nation's critical infrastructure; No single resilience metric or framework could be a solution for these projects to enhance awareness of potential disruptions and predict potential changes in the critical infrastructure sectors (DHS 2020). These measurement metrics are generic, academicwide models that function well as a resilience assessment tool for many systems engineers and managers. However, their broad scope and standardized form limit their usefulness as a quantitative model for evaluating the resilience of a system to a specific disruptive circumstance such as labor shortage.

The proposed methods can be used generically on a wide variety of systems and under different disruptive scenarios. Without precisely defined metrics around system performance, such studies face challenges in assessing system behaviors to a specific disruptive event. Consensus on definitions, metrics, and models for resilient supply chains does not exist, and a comprehensive, systems-based view is necessary for furthering the field of resilience (Golan et al. 2020). Although the concept of measuring resilience of FEW systems was proposed almost a decade ago (Vogt et al. 2012), no study in the literature focuses on measuring resilience of FEW systems to a sudden labor shortage. To build more resilient FEW systems, there is a gap between what we know (e.g., how much labor, water, and energy are required to produce certain amount of food) and what we do not know about the impact of labor shortage on the performance of FEW systems. A contribution of this study to bridge this gap is to specifically assess the ability of FEW systems to reduce the magnitude and/or consequence of labor shortage.

\section{Resilience of FEW systems}

The concept of infrastructure resilience has evolved from the infrastructure's ability to provide the service for which it is intended (or simply system effectiveness) to include other dimensions of performance that an infrastructure system is expected to provide (e.g., cost and reliability). For instance, reliability has been used in the late 1970s, and continued through the $1980 \mathrm{~s}$, as the probability that the expected service will be sustained at acceptable levels for an extended period, generally throughout the design lifetime of the system (Lemer 1996). Therefore, it is necessary to include performance effectiveness, reliability, and cost factors in any measurement of resilience. This section aims to provide a mathematical basis that helps evaluate the impact of a disruptive event (e.g., sudden shortage of labor). Resilience metrics can generally be grouped into two categories: Attribute-based metrics rely on survey responses and subjective weighting values for system properties that can be beneficial to resilience to explore the main attributes of the system affecting resilience. Performance-based metrics are generally quantitative approaches for describing infrastructure system outputs in the event of specified disruptions and formulate metrics of system resilience (Vugrin et al. 2017). 
The present study uses a performance-based approach to quantify the current state of resilience for a system to a specified disruptive event.

The scope of the study does not undermine or question the importance of soft (e.g., consumption behavior, collaboration, community engagement) and other hard factors (e.g., equipment and raw materials) that influence resilience. The authors are aware of the fact that both hard and soft factors play important roles in achieving resilience (Fox-Lent et al. 2015). However, some of these are very difficult to quantify and thus social and community components are not included in the present study.

In this study, the following definitions are used:

- Resilience is the ability of a system to effectively combating (absorbing, adapting to or rapidly recovery from) disruptive events (Mumby et al. 2014).

- The disruptive event(s) is an unwanted situation(s) that makes the system's normal performance level susceptible to disruption (Hu et al. 2008).

- Absorptive capacity is the degree to which a system can absorb the impacts of system disruption and minimize consequences with little effort (Vugrin et al. 2011) (e.g., storage capacity of food or water to overcome supply or production disruption).

- Adaptive capacity is the ability of a system to react to undesirable shocks by undergoing some adjustments (Kebede et al. 2016) (e.g., shift the use of energy or other resources).

- Restorative capacity is the ability of a system to be repaired quickly and return to normal or improved operations and system reliability (Ouyang et al. 2012).

- A sustainable system is a system that can consistently meet its demands with sustainable inputs rather than using non-renewable sources (Karan et al. 2018).

To quantitatively measure resilience and sustainability, the metrics developed by Francis and Bekera (2014) and Karan and Asadi (2018) are adopted in this study. Francis and Bekera proposed a resilience metric that incorporates the three resilience capabilities (absorptive, adaptive, and restorative) and the time to recovery. Karan and Asadi developed an integrated sustainability index that incorporated FEW components. These components each consist of different sub-components (e.g., transportation fuel for the energy component, public supply for the water component, and grains for the food component) that make up integrated FEW systems. The resilience of a system to a specific disruptive event can be determined by total recovery effort, which is a function of the duration of recovery and the recovery costs (Vugrin et al. 2010). The total recovery effort is comprised of adjustments related to the adaptive capacity and restoration efforts to repair the system and return it to normal or improved operations. The adopted metric for resilience does not include the cost dimension, despite the importance of recovery costs following disruptive events. Lack of resilience can result in serious economic implications. For same disruptions, systems disproportionally differ in the degree of economic losses and the economic impact of disruption does not correlate with the size of economy (Kurth et al. 2020). We incorporate a cost dimension into the definition of resilience and proposed the following resilience metrics:

Absorptive capacity resilience metric,

$R_{\text {abs }}=\frac{P_{\mathrm{D}}}{P_{0}}$

Adaptive capacity resilience metric,

$R_{\text {adp }}=\frac{\left(t_{\mathrm{a}}-t_{0}\right)}{t_{\text {slack }}} \times\left(1-\frac{C_{\mathrm{a}}}{C_{\text {aut }}}\right) \times \frac{P_{\mathrm{a}}}{P_{0}}$

Restorative capacity resilience metric,

$R_{\text {res }}=\frac{\left(t_{\mathrm{r}}-t_{\mathrm{a}}\right)}{t_{\text {slack }}} \times\left(1-\frac{\left(C_{\mathrm{r}}-C_{\mathrm{a}}\right)}{C_{\text {aut }}}\right) \times \frac{P_{\mathrm{R}}}{P_{0}}$

Integrated resilience metric,

$R=\frac{\left(t_{\mathrm{r}}-t_{0}\right)}{t_{\text {slack }}} \times\left(1-\frac{C_{\mathrm{r}}}{C_{\text {aut }}}\right) \times \frac{P_{\mathrm{D}}}{P_{0}} \times \frac{P_{\mathrm{a}}}{P_{0}} \times \frac{P_{\mathrm{R}}}{P_{0}}$

where $P_{0}$ is the original stable performance level (before the occurrence of the disruptive event), $P_{\mathrm{D}}$ is the performance level immediately post-disruption and before any recovery efforts, $P_{\mathrm{a}}$ is the performance level after initial adjustments have been made, $P_{\mathrm{R}}$ is the performance at a new stable level after recovery efforts have been exhausted, $t_{0}$ is the start time of the disruptive event, $t_{\mathrm{a}}$ is the time to complete initial adjustments, $t_{\mathrm{r}}$ is the time to final recovery, $t_{\text {slack }}$ is the maximum amount of time post disaster that is acceptable before recovery ensues (varies based on system's function), $C_{\mathrm{a}}$ is the cost needed to complete initial adjustments, $C_{\mathrm{r}}$ is the recovery cost, $C_{\text {aut }}$ is the cost of full automation so systems can perform continuously with no or with minimal human assistance.

The slack time can start from the time of the appearance of a labor shortage due to a disruptive event until the time of full recovery of the system (Nanab et al. 2014). The revised resilience metric is dimensionless and thus can be used in a comparative manner.

Figure 1 better illustrates these metrics and ratios. Consider the impact of COVID-19 on agriculture as a hypothetical example. The first case of the disease labeled as Covid19 is detected at $t_{0}$. Because of this disruptive event, farmers are unable to find enough workers to harvest their crops or care for their animals. After some time, we notice a drastic 
Fig. 1 Time and cost dimensions of system performance under unwanted disruptive situations

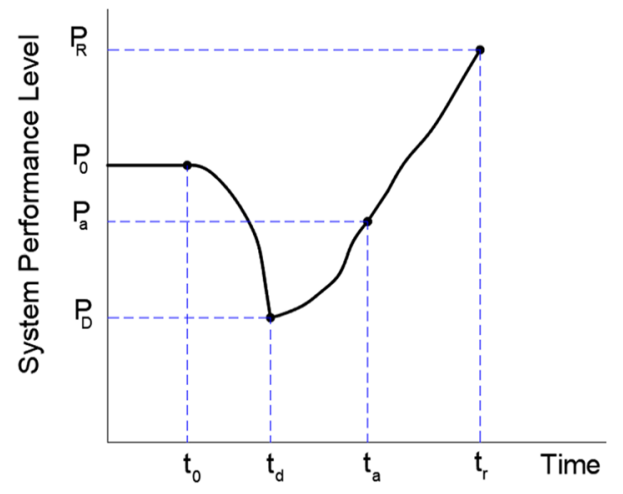

reduction in the overall system performance (e.g., empty shelves of meat). When the performance of the system is at its lowest $\left(P_{\mathrm{D}}\right)$, we start making initial adjustments at $t_{\mathrm{d}}$ such as cutting down on meat and try alternative sources of protein to get the recommended daily intake. The cost of these adjustments is estimated at $C_{\mathrm{a}}$ and it takes $\mathrm{t}_{\mathrm{a}}$ to complete them. Making these adjustments would result in an overall increase in the system's performance and brings the system to a new performance level, $P_{\mathrm{a}}$. With the aid of several different investments (e.g., automation, use of high-tech mechanical ventilation), agriculture is gradually returning to normality and after some time, $t_{\mathrm{r}}$, it may be able to restore most of its services thereby achieving a new equilibrium, $P_{\mathrm{R}}$. The cost of these investments is estimated at $C_{\mathrm{r}}$.

\section{Defining and measuring the system performance}

To capture the performance of an infrastructure system, several measures including cost, quality of service, capacity, safety, and environmental impacts need to be defined and used (Martland 2012). Also, when defining and measuring performance, it is crucial to consider the perspective of entities and stakeholders that are involved or potentially impacted by the infrastructure. Performance monitoring and measurement are at the heart of resilient control systems. The lack of precise definitions and performance measurement tools that span the entire supply systems are the major obstacles to the analysis of the effectiveness of the FEW systems over time. The eventual goal of performance-based resilience metrics is to quantify the system performance after the occurrence of a disruptive event. The system performance can be measured based on the system delivery (e.g., gallons of water not delivered) or greater community impacts such as the number of household days without water or the number of emergency systems without power (Watson et al. 2015). Table 1 lists a set of performance measures for some of the critical infrastructure systems proposed by various researchers. An example of potentially disruptive events for each system is also included in the Table.

A review of resilience metrics presented in Table 1 indicates that FEW demands that are not served and the number (or percentage) of people without service during a specified period are two potential means for performance measurement. Consider the following scenario as an example; Due to a disruptive event, 400 out of 1000 utility customers do not fully access to water service for $2 \mathrm{~h}$. If they experience low or no water pressure, then the first approach better represents the state of resilience for the water system but if customers experience water outages (e.g., shutdown of the water supply), it is likely to be more accurate to use the second approach. To define the system performance, it is quite important to specify essential services of the system, those that must be maintained at close to full capacity through the disruptive event. For example, drinking water is estimated as 1 gallon (or 3.81 ) per day per person, accounting for $1 \%$ of the total household water usage (Blackwood et al. 2017). Drinking water may only be a small portion of our water usage every day, but it is more essential than landscape irrigation, car washing, or even toilet flushing for the water system. The acceptable level of resilience can be defined based on the time and magnitude of essential food, energy, or water supply. For example, water service disruptions for less than 4 hours should be different from those more than $12 \mathrm{~h}$ disruptions.

\subsection{Measuring the performance of water systems}

A water supply system transfers water from a source (e.g., lake, river, or underground) to a treatment or purification facility and then carries the treated/purified water to end users. Sometimes the raw water can be directly transferred to users (e.g., for thermoelectric power). In this study, the performance of water systems is measured based on eight water-use categories included in the U.S. Geological Survey (USGS)'s National Water-Use Science Project; public supply, domestic, irrigation, thermoelectric power, self-supplied industrial, mining, livestock, and aquaculture. Whenever 
Table 1 Proposed performance measurement systems for critical infrastructure systems

\begin{tabular}{|c|c|c|c|}
\hline Infrastructure system & Performance measurement & Disruptive event & Reference \\
\hline Critical networks & $\begin{array}{l}\text { Percentage of nodes functioning; Ratio of a network's actual flow to its } \\
\text { maximum capacity }\end{array}$ & $\begin{array}{l}\text { Natural disasters, } \\
\text { epidemics, and } \\
\text { cyber threats }\end{array}$ & Ganin et al. (2016) \\
\hline Emergency Services & Number of users notified by an emergency alert system & Natural disasters & Choi et al. (2019) \\
\hline \multirow[t]{4}{*}{ Energy } & $\begin{array}{l}\text { Number of events in which voltage levels fall outside a predetermined } \\
\text { range; Duration and percentage of customers affected in a given area }\end{array}$ & Natural disasters & Kwasinski (2016) \\
\hline & Percentage of power supply in its normal value & Hurricane & Ouyang and Wang (2015) \\
\hline & Percentage of maximum gas flow in its normal value & Hurricane & Ouyang et al. (2012) \\
\hline & Lost power times its duration & Intentional Attack & Ouyang and Fang (2017) \\
\hline \multirow[t]{2}{*}{ Transportation systems } & Traffic flow capacity & Earthquake & Bocchini et al. (2014) \\
\hline & Average trip time & N/A & Martland (2012) \\
\hline \multirow[t]{2}{*}{ Water } & Fraction of water supply to demand nodes & N/A & Zhuang et al. (2013) \\
\hline & $\begin{array}{l}\text { Percentage of homes with running water; Average distance to the near- } \\
\text { est clean water in rural villages }\end{array}$ & $\begin{array}{l}\text { Contamination of } \\
\text { drinking water; } \\
\text { Earthquakes; } \\
\text { Tsunamis }\end{array}$ & Martland (2012) \\
\hline
\end{tabular}

possible, each water-use category is further broken down by a number of subcategories to better analyze the time intervals that the water demand is not served. Currently, the subcategory data are only available for Irrigation and Domestic water-use categories.

Table 2 lists the daily freshwater consumption for these water-use categories components, their energy usage, and the (regular) time interval to meet the water demand.
For example, when the time interval for toilet flushing is assumed to be $3 \mathrm{~h}$ (as it is recommended to empty the bladder once every three hours (Schade 2006)), then disruption of water service for $3 \mathrm{~h}$ will not meet the toilet water demand. The discussion on the length of the time interval is crucial and the periods reported here are not meant to be conclusive or significant. The U.S. Energy Information Administration (EIA), the Environmental Protection
Table 2 Estimated use of water per capita ( 2 psi pressure $\approx 5$ $\mathrm{ft}$ head)

\begin{tabular}{|c|c|c|c|c|}
\hline Water use & $\begin{array}{l}\text { Usage (gal per } \\
\text { day) }\end{array}$ & $\begin{array}{l}\text { Electricity usage (Wh } \\
\text { per gal) }\end{array}$ & $\begin{array}{l}\text { Time interval } \\
\text { (h) }\end{array}$ & $\begin{array}{l}\text { Desired } \\
\text { pressure } \\
\text { (psi) }\end{array}$ \\
\hline Thermoelectric & 297 & N/A & 0.5 & 2 \\
\hline Irrigation & 368 & 2.08 & & 2 \\
\hline Fruits & 41 & & 82 & \\
\hline Vegetable & 20 & & 96 & \\
\hline Grains & 286 & & 305 & \\
\hline Oils & 20 & & 158 & \\
\hline Domestic & 73 & 2.84 & & \\
\hline Drinking & 1 & & 2 & 50 \\
\hline Bathroom faucets & 7 & & 3 & 50 \\
\hline Toilet water & 23 & & 3 & 20 \\
\hline Dishwasher/kitchen sink & 8 & & 5 & 50 \\
\hline Shower & 14 & & 16 & 50 \\
\hline Laundry & 18 & & 168 & 40 \\
\hline Irrigation & 2 & & 240 & 20 \\
\hline Public supply & 49 & 2.35 & 198 & 20 \\
\hline Industrial & 44 & 2.57 & 48 & 20 \\
\hline Aquaculture & 24 & 1.85 & 336 & 15 \\
\hline Mining & 6 & 2.50 & 48 & 50 \\
\hline Livestock & 6 & 2.50 & 2.6 & 15 \\
\hline
\end{tabular}


Agency (EPA), and the USGS are the sole sources of the data presented in Table 2 (Dieter et al. 2018; EIA 2017; EPA 2010). The desired pressures in water distribution systems are obtained from Ghorbanian et al. (2016). Please note that the water usage values describe the amount of water withdrawn from water sources and do not necessarily represent water consumptions that are permanently lost from their sources.

Looking at the national patterns of water use indicate that the largest demand for water use in the US is irrigation with around 118 billion gallons per day (42\% of freshwater use), followed by a thermoelectric generation with around 98 billion gallons per day ( $34 \%$ of freshwater use), other wateruse categories need energy to supply water through pumping, transportation, and treatment. Thermoelectric power plants using wet cooling systems require large amounts of water to produce electricity. These power plants can potentially operate $24 / 7 / 365$ except for maintenance periods and unexpected outages. Therefore, their time interval is very short. Irrigation water use is accounted for sustaining plant growth in agricultural and horticultural practices. Different types of plants need different amounts of water. The irrigation sub-components adopted in the study are food patterns suggested by the U.S. Departments of Agriculture (USDA 2015). To determine the irrigation frequencies (time interval), a dataset of common foods (between 3 and 15 options) was prepared and the required amounts of water and light, average yield per plant, and other relevant requirements (e.g., chilling requirements representing the number of hours at $7{ }^{\circ} \mathrm{C}$ or less for fruits and vegetables) were taken into consideration.

Public supply water is delivered to commercial users and used for public purposes such as firefighting, street washing, and maintaining municipal parks. The average time interval a US fire department responds to a fire is used for the analysis. Manufacturing and other fabricating industries use water for producing, processing, cooling, or transporting a product. Lizarraga (2013) identified the capacity for resilience of water utility disruption events by interviewing 288 businesses that experienced contamination events and water outages. The analysis was reported for a 6-day water outage event and businesses in construction, manufacturing, and transportation reported temporarily closing for $33.2 \%$ of the total duration of the event. It is assumed that industrial

$P_{\mathrm{W}}=\left\{\begin{array}{ll}\frac{\sum_{(n-1) \times t_{\text {int }}}^{(n) \times t_{\text {int }}} \min \left(W_{\mathrm{S}}, W_{\mathrm{D}}\right) \times \min \left(P_{\mathrm{S}}, P_{\mathrm{D}}\right) \times t_{\text {int }}}{W_{\mathrm{D}} \times P_{\mathrm{D}} \times t_{\text {slack }}} & \text { if } Q_{\mathrm{S}} \geq Q_{\mathrm{D}} \\ 0 & \text { if } Q_{\mathrm{S}}<Q_{\mathrm{D}}\end{array} \quad\right.$ and $n=1,2,3, \ldots$ water users will face difficulties in performing their activities during water outage events for more than $48 \mathrm{~h}$.

Aquaculture water use is water associated with breeding, raising, and harvesting of organisms (e.g., fish) in water. Water reuse is practiced in most aquaculture units, but still, regular water replacement is necessary to maintain adequate water quality. The water replacement intervals depend largely on the oxygen level of the water, stocking density, and the type of feed given to the organisms but it is recommended to change the water at least once in two weeks (Boyd and Tucker 2012).

Mining water use includes quarrying, mineral processing, injection of water for secondary oil recovery, or unconventional oil and gas recovery (such as hydraulic fracturingmostly saline water), and other operations associated with mining activities. We did not find information related to the performance consequence of water supply disruption on mining activity, but the time interval for industrial use could be used due to the similarity between these two categories. Last, livestock water use is water associated with livestock watering, feedlots, dairy operations, and other on-farm needs. Most of the animals (dairy cows, beef cattle, sheep, and lambs) can only live about seven days without water and they should be given all the water they can drink. Livestock water use may vary greatly depending on the kind and size of the animal, feed intake, activity level, physical state, and environmental temperature. We have compiled the drinking behavior of dairy cows from a few studies to determine the minimum time interval to supply water for livestock use (Cardot et al. 2008; Houpt 2018; Huzzey et al. 2005).

To track water utility performance, a benchmarking program led by the American Water Works Association (AWWA) has been influential in setting guidelines to gauge water system performance levels and, when tracked over time, the performance trends. Disruptions of water service (outages/1000 accounts) for three time periods $(<4$ h, 4-12 h, > 12 h) and available water supply to current water demand (\%) are performance indicator specific to the water sector developed and suggested by this association (AWWA 2019). We adopt these indicators and expand them with more attributes. The performance of a water system is characterized by three attributes: pressure, quantity (flow), and quality, and measured by the period(s) the water supply is disrupted. The following equation is developed to calculate the performance of the water system: 
where $P_{\mathrm{W}}$ is the water system performance, $t_{\text {int }}$ is the time interval in hour (see Table 2), $W_{\mathrm{s}}$ is the amount of water supply (flow) in gpd, $W_{\mathrm{D}}$ is the desired water demand in gpd (see Table 2), $P_{\mathrm{s}}$ is the pressure in the water supply in psi, $P_{\mathrm{D}}$ is the desired water pressure in psi (see Table 2), $Q_{\mathrm{s}}$ is the quality in the water supply, $Q_{\mathrm{D}}$ is the desired water quality.

The following example illustrates this performance metric: A water utility system is designed to supply drinking water for a town with 160 people. The desired water demand,

$$
\begin{aligned}
& P_{\mathrm{W}}(t=0-2)=\frac{\sum_{0}^{2} \min (9,10) \times \min (50,50) \times 2}{10 \times 50 \times 2}=90 \% \\
& P_{\mathrm{W}}(t=2-4)=\frac{\sum_{0}^{2} \min (11,10) \times \min (49,50) \times 2}{10 \times 50 \times 2}=98 \% \\
& P_{W}(t=4-6)=\frac{\sum_{0}^{2} \min (6,10) \times \min (50,50) \times 2}{10 \times 50 \times 2}=60 \%
\end{aligned}
$$

$P_{\mathrm{W}}(t=0-10)=\frac{2 \times(9 \times 50+10 \times 49+10 \times 50+6 \times 50+10 \times 50)}{10 \times 50 \times 10}=89.6 \%$

$W_{\mathrm{D}}$, for a 16 -h day is 160 gallons per day (note: $t_{\text {int }}=2 \mathrm{~h}$, $P_{\mathrm{D}}=50 \mathrm{psi}$ ). The amount, pressure, and quality of the water supply are measured on an hourly basis. Figure 2 shows the measured data and the system performance. For the first 2-h period (0-2), only 18 out of 20 gallons have been supplied therefore the performance is $90 \%$. For the second $2-\mathrm{h}$ period (2-4), the amount of water supply met the demand, however, the water pressure has been measured 48 psi during the $3-4 \mathrm{~h}$ period, therefore, the performance is increased to $98 \%$. The quality of water did not meet the requirement during the 6-8 h period therefore the performance is only $60 \%$. The overall performance for this $10-\mathrm{h}$ measured period is $89.6 \%$. The calculations for these three time periods are provided below:

\subsection{Measuring the performance of energy systems}

Even though energy exists in many different forms, the performance of energy systems in this study is measured based on two broad categories: electricity and transportation fuel. These two categories dominate the energy market and are sufficient to describe the performance of different energy forms. Measurement of the system performance should indicate to what extent the energy production and supply meet the demand. The performance of a transportation fuel energy system is easy to measure because this form of energy can be stored (e.g., gasoline or aviation fuel can be stored underground in buried tanks). The performance of the energy system-transportation

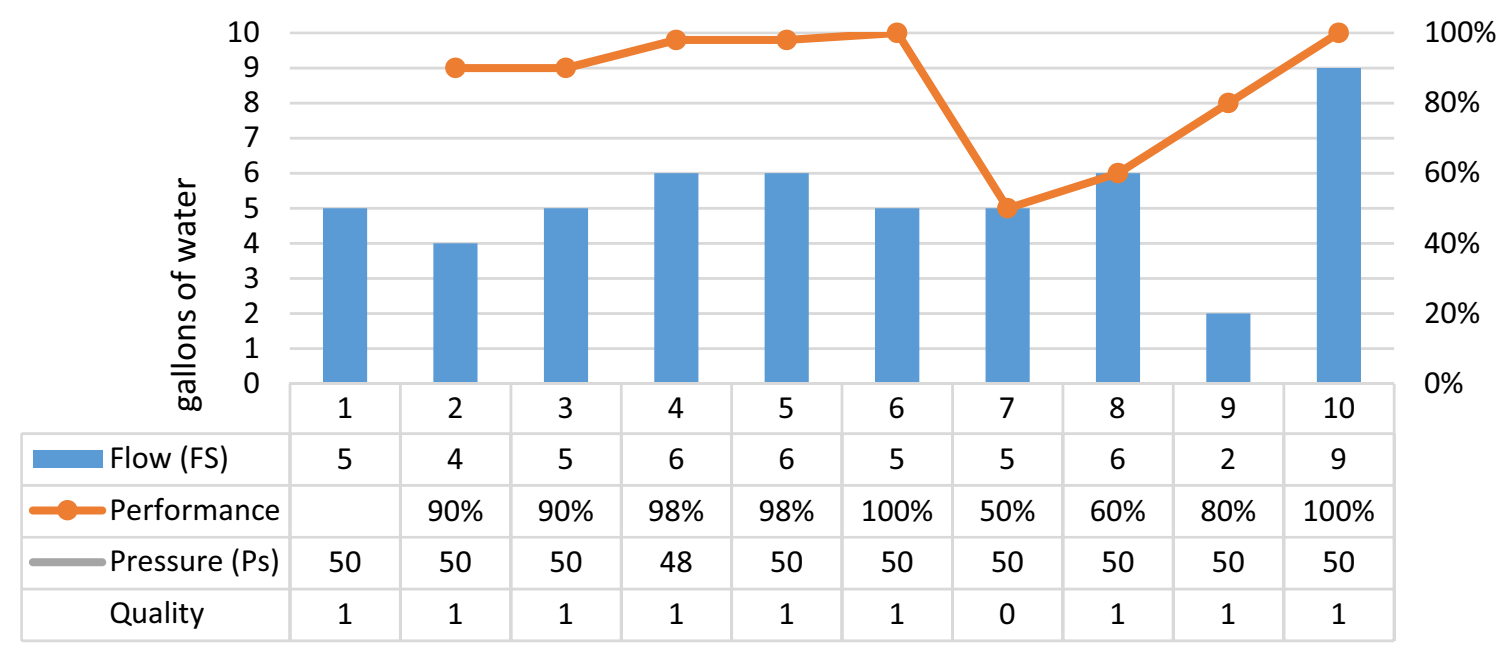

Fig. 2 Performance measurement for a hypothetical water system 
fuel is measured by the ratio of supply to demand. The energy system-electricity is not that straightforward and both power outage frequency and duration must be considered to measure the performance. The supply-demand ratio does not reflect the brief power outages lasting for a few seconds. However, the survey studies supported by the U.S. Department of Energy showed that the impact of brief service interruptions (1-2 s) is approximately equal to 10-25 min outage (Campbell and Lowry 2012; LaCommare and Eto 2006; Lawton et al. 2003). A conservative approach to consider the outage frequency would be to add $10 \mathrm{~min}$ to each momentary outage. Furthermore, as the length of the outage increases, the negative impact of reduced performance could become greater. This impact depends not only on the duration, but also the season, time of day, and even day of the week are contributing attributes. We only take the outage duration into account for performance measurement intending to generalize the results to a wider energy system. The data from prior power outage cost or lost value studies were gathered and combined in this research to understand this relationship (Balducci et al. 2002; Hashemi et al. 2018; Küfeoğlu and Lehtonen 2015; Reichl et al. 2013). Because the datasets were gathered differently (e.g., 1/3-1-4 h outage periods versus $1-4-8-24 \mathrm{~h}$ outage periods or $\$$ per interruption versus $\$ / \mathrm{KWh}$ ), a relative cost and linear interpolations are used to standardize and convert them. The results for five sectors and their mean values are presented in Figure 3. Although the performance of the energy system for each sector decreases substantially as the outage duration increases but mean (aggregated) values show a linear relationship between the outage duration and the performance.

The performance of an energy system-electricity is measured by the period(s) in which the power supply is disrupted and characterized by three attributes: power supply, voltage, and number of outages. The following equation is developed to calculate the performance of the energy system:

$P_{\mathrm{E}}= \begin{cases}\frac{E_{\mathrm{S}} \times V_{\mathrm{S}} \times\left(N_{\text {out }} \times t_{\text {eqv }}+t_{\text {out }}\right)}{E_{\mathrm{D}} \times V_{\mathrm{D}} \times W_{\mathrm{D}} \times W_{\mathrm{D}} \times t_{\text {slack }}} & \text { if } V_{\mathrm{S}} \geq V_{\text {min }} \\ 0 & \text { if } V_{\mathrm{S}}<V_{\text {min }}\end{cases}$

where $P_{\mathrm{E}}$ is the energy system performance, $E_{\mathrm{s}}$ is the amount of power supply, $E_{\mathrm{D}}$ is the amount of power demand, $V_{\mathrm{s}}$ is the voltage in the electricity supply, $V_{\mathrm{D}}$ is the desired electricity voltage, $V_{\min }$ is the minimum electricity voltage below which electric devices will not operate, $t_{\mathrm{eqv}}$ is the equivalent time period with similar impact on the performance per power outage (e.g., $10 \mathrm{~min}$ ), $t_{\text {out }}$ is the duration of the power outage, $N_{\text {out }}$ is the total number of the power outage

\subsection{Measuring the performance of food systems}

The food system is a multidimensional network that integrates production, processing, distribution, and consumption: The availability and accessibility of the food supply directly affect the consumers (social dimension). There is a significant balance between high-quality food and human health (Segneanu et al. 2018). The dependence of agriculture on natural resources such as soil and water related to the environmental dimension. And the relative economic contribution of production agriculture cannot be disregarded
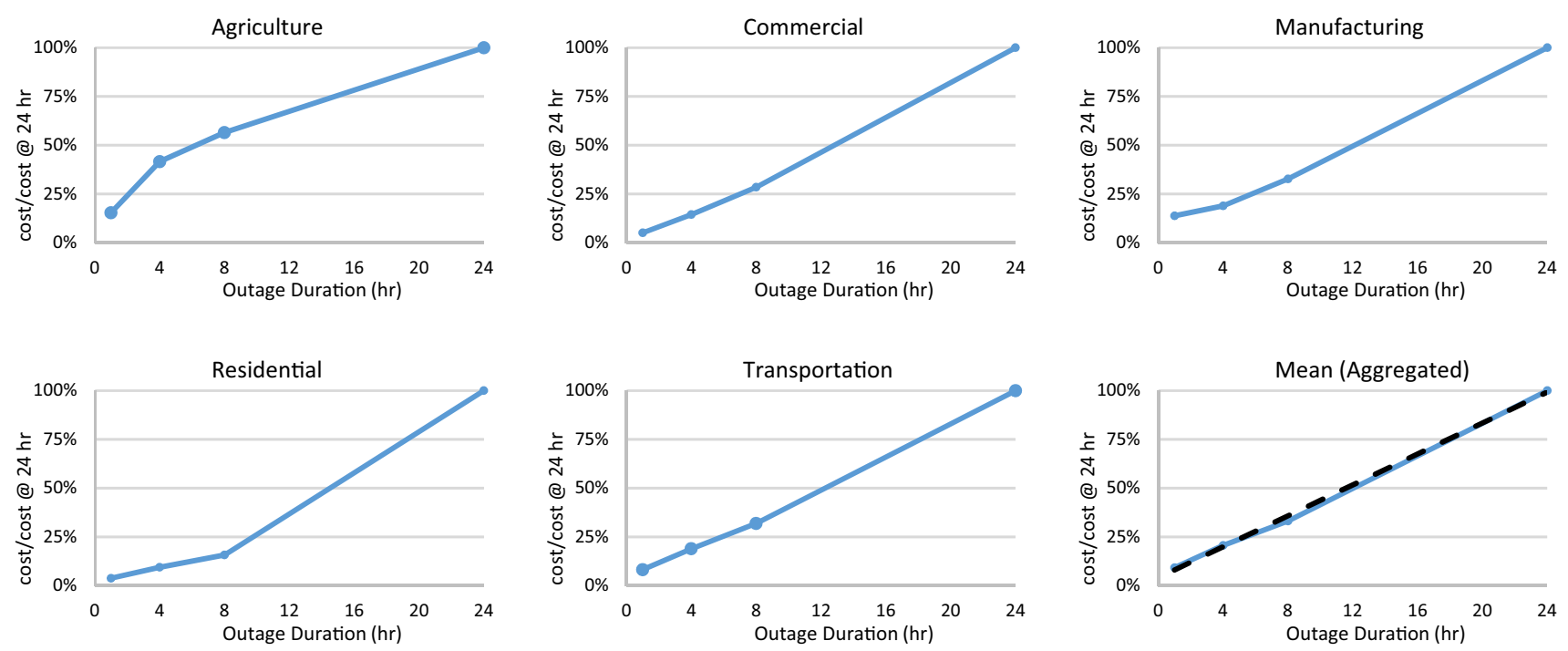

Fig. 3 Power outage costs for sector electricity customers 
Table 3 Recommended intake amounts for a household with energy and water footprints

\begin{tabular}{lclll}
\hline Category & $\begin{array}{l}\text { Consump- } \\
\text { tion (lb per } \\
\text { week) }\end{array}$ & $\begin{array}{l}\text { Time } \\
\text { interval } \\
\text { (day) }\end{array}$ & $\begin{array}{l}\text { Water foot- } \\
\text { print (gal } \\
\text { per lb) }\end{array}$ & $\begin{array}{l}\text { Energy } \\
\text { footprint (Wh } \\
\text { per lb) }\end{array}$ \\
\hline Vegetables & 21.0 & 4.4 & 38.6 & 299.9 \\
Fruits & 13.7 & 4.4 & 115.3 & 643.8 \\
Grains & 8.1 & 4.4 & 197.0 & 781.2 \\
Dairy & 27.7 & 4.4 & 122.2 & 344.0 \\
Protein & 6.8 & 4.4 & 935.0 & 504.0 \\
$\quad$ Foods & & & & \\
Oils & 1.2 & 14 & 283.3 & 520.4 \\
\hline
\end{tabular}

(economic dimension) (IOM and NRC 2015). For this paper, two measures of performance are important: a measure of quantity is the amount of food produced, and quality characterizes nutrition, taste, and dietary components relative to a benchmark, such as the dietary information provided by the Food and Agriculture Organization (FAO) of the United Nations(UN) (Kennedy et al. 2011). These two dimensions are used to measure the performance based on six food groups of the dietary recommendations set forth by the USDA. Thus, the performance of a food system is characterized by quantity and quality dimensions and measured by the time period(s) the food supply is disrupted. The following equation is developed to calculate the performance of the food system:

$P_{\mathrm{F}}=\left\{\begin{array}{ll}\frac{\sum_{(n-1) \times x_{\text {int }}}^{(n)} \min \left(F_{\mathrm{S}}, F_{\mathrm{D}}\right) \times t_{\text {int }}}{W_{\mathrm{D}} \times t_{\text {slack }}} & \text { if } Q_{\mathrm{S}} \geq Q_{\mathrm{D}} \\ 0 & \text { if } Q_{\mathrm{S}}<Q_{\mathrm{D}}\end{array} \quad\right.$ and $n=1,2,3, \ldots$

where $P_{\mathrm{F}}$ is the food system performance, $t_{\text {int }}$ is the time interval (see Table 3 ), $F_{\mathrm{s}}$ is the amount of food supply, $F_{\mathrm{D}}$ is the desired food demand (see Table 3 ), $Q_{\mathrm{s}}$ is the quality in the food supply, $Q_{\mathrm{D}}$ is the desired food quality.

Table 3 lists the recommended amounts of food from each food group for a moderately active household consisting of one male and one female adult, 36 to 40 years old, and a child, 10 years old. This study uses the data of average male and female adults and children in the US; For adults, the reference male is $5 \mathrm{ft}$ and 10 in $(178 \mathrm{~cm})$ tall and weighs $197.8 \mathrm{lb}(89.7 \mathrm{~kg})$ who needs 2600 calories per day, and the reference woman is $5 \mathrm{ft} 3$ in $(162 \mathrm{~cm})$ tall and weighs $170.5 \mathrm{lb}(77.3 \mathrm{~kg}$ ) who needs 2000 calories per day (Fryar et al. 2018). For children, the reference boy is $4 \mathrm{ft}$ and 8 in $(142 \mathrm{~cm})$ tall and weighs $85 \mathrm{lb}(38.5 \mathrm{~kg})$ who needs 1800 calories per day, and the reference girl is $4 \mathrm{ft} 8$ in $(143 \mathrm{~cm})$ tall and weighs $88 \mathrm{lb}(39.9 \mathrm{~kg})$ who needs 1800 calories per day. Since the average household size in the US is 2.6 people, only $60 \%$ of a child's consumption is considered for the calculation of the total household consumption (MacDonald and Reitmeier 2017)). The number of calories needed for this household is estimated to be $39,760 \mathrm{cal} / \mathrm{wk}$ (or 5680 $\mathrm{cal} /$ day). Food is generally consumed after being stored in a cool, dry place. Unlike the electricity or even water, the time interval is not necessarily the recommended number of daily or weekly servings of each food group. Grocery shopping frequency for each food group serves as a basis for time intervals. A survey of 2145 regular shoppers of groceries, sponsored by the Food Marketing Institute (FMI) Foundation, indicates that U.S. consumers aged 18 and older make 1.6 trips per week on average (FMI 2017). The average energy consumption and water footprints for each food group are also included in this table. The water data are adopted from Mekonnen and Hoekstra (2010) and the energy data are compiled from Ladha-Sabur et al. (2019).

\section{Measuring labor intensity}

The objective of this study is to assess the impact of a sudden labor shortage on the resilience of FEW systems. Therefore, it is important to measure the labor intensity of FEW productions. In general, labor intensity is measured by the amounts of labor used to produce goods or services. We adopt the approach that the U.S. Bureau of Labor Statistics (BLS) uses to measure the labor intensity and evaluate the labor-intensive industries (BLS 2019); the ratio of the employed population to the unit of production. This measure indicates the extent to which FEW systems absorb labor for each unit of production. It is difficult to distinguish the output of FEW workers from other establishments since multiple industries and critical infrastructure systems work and interact with each other to produce and ultimately deliver the service to their end users. For instance, equipment operators, truck drivers, or even certain administrative positions are simultaneously working for multiple employers and crossindustry boundaries to provide FEW services. To measure the labor intensity of FEW productions, we focus on the workforce directly involved in the production, distribution, delivery, operation, and governance of FEW systems in the US. We primarily use the North American Industry Classification System (NAICS) to classify business establishments related to FEW systems. The NAICS is updated every 5 years to collect and publish statistical data related to the U.S. business economy. The 2017 standard is the most recent version at the time of this study, which is valid through 2022. The employment data established under NAICS are then integrated and compared with the employment data publicly available from the BLS Occupational Employment Statistics (OES) program to classify the most relevant jobs and their employment linked to FEW systems. Once industries and most relevant occupations are identified, the last step is to 
calculate how much employment is related to each category of FEW systems (as listed in Tables 2 and 3). Defining a precise range of occupations for each category (e.g., water use for mining) is a challenging task due to the way that NAICS and BLS employment data are gathered and expressed in a summary form.

\subsection{Labor intensity of water systems}

The water sector covers an extensive spectrum of occupations and business establishments, from utilities management, administration, and customer service to construction and engineering industries that supply goods and services to support water-related activities. Although we only consider those industries and occupations that directly provide water (e.g., water lines and wastewater treatment) or essential services, it is expected to have significant overlap between water workers and other industries, including energy production and distribution. A list of six business establishments has been identified, with relevant sub-industries highlighted in Table 4. The information covers the most relevant industries linked to water production and distribution systems.

In addition to water-related industries, occupational employment data from the BLS OES program is used to classify the water-related occupations. Jobs directly involved in the design, construction, operation, maintenance, and administrative and governance of water systems and their physical assets are taken into consideration. Office and Administrative Support Occupations (group ID 43), Construction and Extraction Occupations (group ID 47), and Production Occupations (group ID 51) are major waterrelated groups. A list of these occupational groups is highlighted in Table 5.

Table 4 Business establishments related to water systems (NAICS 2017)

\begin{tabular}{llllr}
\hline Sector & Category & Code & Description & Est. employment \\
\hline Utilities & Thermoelectric & $22-111$ & Electric Power Generation & 3692 \\
& Domestic and Public Supply & $22-131$ & Water Supply \& Irrigation Systems & 38,510 \\
Construction & All Water Categories & $23-711$ & Water Line and Related Structures Construction & 146,957 \\
& Domestic and public supply & $23-822$ & Plumbing contractors & 103,976 \\
Professional, Scientific, & All water categories & $54-162$ & Environmental Consulting Services & 88,391 \\
$\begin{array}{l}\text { and Technical Services } \\
\text { Public administration }\end{array}$ & Domestic and public supply & $92-11$ & Local government, excluding schools and hospitals & 244,500 \\
\hline
\end{tabular}

Table 5 Occupations in water systems (BLS 2019)

\begin{tabular}{lllll}
\hline Sector & Code & Description & Est. employment & Related categories \\
\hline Architecture and engineering & $17-2081$ & Environmental engineers & 53,150 & All categories \\
Office and admin. support & $43-5040$ & Meter readers, utilities & 30,450 & Domestic and public supply \\
Construction and extraction & $47-2151$ & Pipelayers & 36,270 & All categories \\
& $47-2152$ & Plumbers, pipefitters, and steamfitters & 442,870 & Domestic and public supply \\
Production & $51-8030$ & Water and wastewater treatment plant and & 123,730 & All categories \\
& & system operators & & \\
\hline
\end{tabular}

Table 6 Labor intensity of water systems

\begin{tabular}{lccc}
\hline Category & $\begin{array}{c}\text { Water supply (million gal- } \\
\text { lons per day) }\end{array}$ & Est. employment & $\begin{array}{l}\text { Labor intensity (M } \\
\text { gal per day/worker) }\end{array}$ \\
\hline Thermoelectric & 98,000 & 5040 & 19.4 \\
Irrigation & 118,000 & 17,575 & 6.7 \\
Domestic & 39,000 & 418,165 & 0.1 \\
Public supply & 12,440 & 133,380 & 0.1 \\
Industrial & 14,800 & 9055 & 1.6 \\
Aquaculture & 7550 & 1125 & 6.7 \\
Mining & 4000 & 2450 & 1.6 \\
Livestock & 2000 & 300 & 6.7 \\
\hline
\end{tabular}


As can be seen in Tables 4 and 5, some of the waterrelated workforce data are unique to a particular water use, while others are shared among all categories. To aggregate and combine this data with the total U.S. water supply, the average price of delivering a unit quantity of water (e.g., one gallon) to consumers is used. The higher the price, the greater number of workers. The average price of domestic and public supply water uses are the most expensive at 14 times the price of water for irrigation, livestock, and aquaculture uses, 15 times the price of water for industrial and mining uses, and 65 times the price of water for thermoelectric use. For water use categories at the same price, the estimated employment is distributed according to the water supply values. The estimated employment and labor intensity for each water-use category are shown in Table 6.

\subsection{Labor intensity of energy systems}

In addition to the employment data from the BLS, the data collected on behalf of the U.S. Department of Energy (DOE) for 2019 are used here to measure the labor intensity of the U.S. Energy system (Barrett and Yudken 2020). The energy system can be categorized into two main classes: transportation fuel and electricity. These two classes of energy can cover all forms of energy. Even energy forms such as natural gas or firewood, not traditionally a transportation fuel or electricity class, can be converted or used to produce transportation fuel or electricity. Table 7 lists energyrelated employment in the U.S. national production, and labor intensity. All occupations related to fuel extraction, processing (e.g., oil refineries), and production (e.g., corn ethanol) are included in the transportation fuel employment data. The electricity class covers all occupations related to power generation, distribution, and maintenance. While the electricity generation can be distinguished by energy source, transmission and distribution sectors encompass the employment associated with the entire network of power lines that transmit electricity from generating stations to customers regardless of the energy source. This sector alone employs nearly 884,800 people. Neither NAICS codes nor BLS occupations address this distinction effectively. Therefore, the employment data are distributed according to the generation share of electricity by energy source (natural gas: $38.4 \%$, coal: $23.5 \%$, Nuclear: $19.7 \%$, Renewables: $17.5 \%$, other: $0.9 \%)$. To better understand the scale of measurements in Table 7, consider the national daily average of about 3.03 gallons of finished motor gasoline consumption and 30.5 kWh per household (EIA 2020). Fuel gallon equivalent allows us to compare the energy content of transportation fuels against a commonly known energy source such as electricity. One gallon of gasoline has the energy of $34 \mathrm{kWh}$ electricity.

\subsection{Labor intensity of food systems}

The food sector captures a wide range of agriculture and farm-related industries. In 2018, 22.0 million full- and parttime jobs were related to the agricultural and food sectors, direct on-farm employment accounted for about 2.6 million of these jobs (USDA 2018). The business establishments involved in overseeing the food system are identified based on the NAICS. Only those directly involved in the production and distribution are chosen. A list of eighteen business establishments has been identified, with relevant subindustries highlighted in Table 8. Because of the tremendous overlap between food-related establishments and due to lack
Table 7 Labor intensity of energy systems

\begin{tabular}{|c|c|c|c|}
\hline Category & Daily energy supply & Est. employment & Daily labor intensity \\
\hline \multicolumn{4}{|l|}{ Transportation fuel } \\
\hline Petroleum & $\begin{array}{l}715.7 \mathrm{M} \mathrm{gal} \\
(5950 \mathrm{Btu})\end{array}$ & 615,528 & $\begin{array}{l}1,163 \text { gal per day/worker } \\
\text { ( } 0.0097 \text { Btu per day/worker) }\end{array}$ \\
\hline Ethanol/Biofuel & $\begin{array}{l}96.2 \mathrm{M} \mathrm{gal} \\
(800 \mathrm{Btu})\end{array}$ & 107,914 & $\begin{array}{l}891 \text { gal per day/worker } \\
(0.0074 \text { Btu per day/worker) }\end{array}$ \\
\hline \multicolumn{4}{|l|}{ Electricity } \\
\hline Natural gas & $\begin{array}{l}4,334 \mathrm{kWh} \\
(14.8 \mathrm{MMBtu})\end{array}$ & 616,168 & $\begin{array}{l}\text { 7.0 Wh per day/worker } \\
\text { (24.0 Btu per day/worker) }\end{array}$ \\
\hline Coal & $\begin{array}{l}2,647 \mathrm{kWh} \\
(9.0 \mathrm{MMBtu})\end{array}$ & 354,056 & $\begin{array}{l}\text { 7.5 Wh per day/worker } \\
\text { (25.6 Btu per day/worker) }\end{array}$ \\
\hline Nuclear & $\begin{array}{l}2,216 \mathrm{kWh} \\
(7.6 \mathrm{MMBtu})\end{array}$ & 244,315 & $\begin{array}{l}\text { 9.1 Wh per day/worker } \\
\text { (31.1 Btu per day/worker) }\end{array}$ \\
\hline Renewables & $\begin{array}{l}1,973 \mathrm{kWh} \\
\text { (6.7 MMBtu) }\end{array}$ & 409,695 & $\begin{array}{l}\text { 4.8 Wh per day/worker } \\
\text { (16.4 Btu per day/worker) }\end{array}$ \\
\hline Other & $\begin{array}{l}101 \mathrm{kWh} \\
(0.3 \mathrm{MMBtu})\end{array}$ & 11,568 & $\begin{array}{l}8.8 \mathrm{Wh} \text { per day/worker } \\
\text { (30.0 Btu per day/worker) }\end{array}$ \\
\hline
\end{tabular}


Table 8 Business establishments related to food systems (NAICS 2017)

\begin{tabular}{|c|c|c|c|c|}
\hline Sector & Category & Code(s) & Description & Est. employment \\
\hline \multirow{16}{*}{$\begin{array}{l}\text { Agriculture, Forestry, } \\
\text { Fishing and Hunting }\end{array}$} & \multirow[t]{2}{*}{ Vegetables } & $11-12$ & Vegetable and Melon Farming & 106,527 \\
\hline & & $11-141$ & Food Crops Grown Under Cover & 24,019 \\
\hline & Fruits & $11-13$ & Fruit and Tree Nut Farming & 184,450 \\
\hline & \multirow[t]{4}{*}{ Grains } & $11-114$ & Wheat Farming & 27,136 \\
\hline & & $11-115$ & Corn Farming & 129,810 \\
\hline & & $11-116$ & Rice Farming & 3860 \\
\hline & & $11-113$ and $11-119$ & All Other Grain Farming & 60,495 \\
\hline & Dairy & $11-212$ & Dairy Cattle and Milk Production & 94,327 \\
\hline & \multirow[t]{2}{*}{ Oils } & $11-111$ & Soybean Farming & 86,701 \\
\hline & & $11-112$ & Oilseed (except Soybean) Farming & 15,562 \\
\hline & \multirow[t]{6}{*}{ Protein Foods } & $11-211$ & Beef Cattle Ranching and Farming, including Feedlots & 137,674 \\
\hline & & $11-22$ & Hog and Pig Farming & 39,188 \\
\hline & & $11-23$ & Poultry and Egg Production & 44,743 \\
\hline & & $11-24$ & Sheep and Goat Farming & 1454 \\
\hline & & $11-25$ & Aquaculture & 4582 \\
\hline & & $11-41$ & Fishing & 6474 \\
\hline \multirow[t]{8}{*}{ Manufacturing } & Fruits & $31-14$ & Fruit Preserving and Manufacturing & 56,230 \\
\hline & \multirow[t]{3}{*}{ Grains } & $31-121$ & Flour Milling and Malt Manufacturing & 25,566 \\
\hline & & $31-123$ & Breakfast Cereal Manufacturing & 13,228 \\
\hline & & $31-18$ & Bakeries and Tortilla Manufacturing & 156,791 \\
\hline & Dairy & $31-15$ & Dairy Product Manufacturing & 142,742 \\
\hline & Oils & $31-122$ & Starch and Vegetable Fats and Oils Manufacturing & 22,095 \\
\hline & \multirow[t]{2}{*}{ Protein Foods } & $31-16$ & Animal Slaughtering and Processing & 506,311 \\
\hline & & $31-17$ & Seafood Product Preparation and Packaging & 33,618 \\
\hline
\end{tabular}

Table 9 Occupations in food systems (BLS 2019)

\begin{tabular}{lllll}
\hline Sector & Code & Description & Est. employment & Related categories \\
\hline Food preparation and serving & $35-2021$ & Food Preparation Workers & 863,740 & All categories \\
Farming, fishing, and forestry & $45-0000$ & Farming, Fishing, \& Forestry & 418,780 & All categories \\
Production & $51-3020$ & Butchers \& Other Meat, Poultry, \& & 364,150 & Protein foods \\
& & Fish Processing & \\
\hline
\end{tabular}

of statistical benchmark, establishments such as Grocery and Related Product Merchant Wholesalers (NAICS code 4244), Food and Beverage Stores (NAICS code 442), Food Services and Drinking Places (NAICS code 722) and even Support Activities for Crop Production (NAICS code 1151) are excluded in the analysis.

In addition to the food-related industries, this study analyses occupational employment data from the BLS OES program to further explore the food-related workforce. Food Preparation and Serving Related Occupations (group ID 35) and Farming, Fishing, and Forestry Occupations (group ID 45) are major occupation groups that have significantly high shares of the food-related workforce. A list of three occupational groups has been identified, with relevant occupations highlighted in Table 9. While national levels of employment serve as a foundation for our food-related employment, it should be borne in mind that these data are estimates not actual counts of the number of occupations in the USA

After the food-related workforce data are gathered, the direct production and processing employment numbers for each food category are aggregated and combined with the total U.S. food production to calculate the labor intensity for the food system. As shown in Table 10, the labor intensity is measured based on the full-time worker per unit of production to be consistent with the recommended intake amounts listed in Table 3. The food production data are collected from USDA Yearbook Data (Kenner and Kramer 2019; Parr et al. 2018) and Liddel and Yencho (2020). 
Table 10 Labor intensity of food systems

\begin{tabular}{llccc}
\hline Category & Sub-category & $\begin{array}{l}\text { Production (mil- } \\
\text { lion lb) }\end{array}$ & Est. employment & $\begin{array}{l}\text { Labor inten- } \\
\text { sity (M lb/ } \\
\text { worker) }\end{array}$ \\
\hline Vegetables & Grown in field operation/ & 124,041 & 230,700 & 0.54 \\
Fruits & inder cover & 47,388 & 356,770 & 0.13 \\
Grains & Fruits & 113,109 & 61,960 & 1.83 \\
& Wheat & 807,526 & 286,950 & 2.81 \\
& Corn & 22,421 & 6820 & 3.29 \\
& Rice & 104,801 & 142,490 & 0.74 \\
Dairy & All other grains & 218,382 & 244,880 & 0.89 \\
Oils & Dairy & 24,290 & 159,270 & 0.15 \\
& Soybean & 12,578 & 33,550 & 0.37 \\
Protein Foods & Oilseed & 27,177 & 543,220 & 0.05 \\
& Red meat except pork & 26,330 & 153,000 & 0.17 \\
& Pork & 49,162 & 315,580 & 0.16 \\
& Chicken and turkey & 8126 & 64,800 & 0.13 \\
& Fish and seafood & 14,157 & N/A & N/A \\
\hline
\end{tabular}

Table 11 Share of occupations in the energy and water productivity

\begin{tabular}{llllc}
\hline System & Occupation class & $\begin{array}{l}\text { Occupation } \\
\text { share }(\%)\end{array}$ & $\begin{array}{l}\text { Hourly wage } \\
\text { (median) }\end{array}$ & $\begin{array}{l}\text { Productivity } \\
\text { share (\%) }\end{array}$ \\
\hline Water & Production \& Manufacturing & 22 & $\$ 23.8$ & 17 \\
& Maintenance \& Repair & 37 & $\$ 27.4$ & 33 \\
& Administrative \& Customer Service & 14 & $\$ 18.3$ & 8 \\
& Management \& Business & 10 & $\$ 51.0$ & 17 \\
& Sales & 5 & $\$ 44.2$ & 7 \\
& Other & 12 & $\$ 44.5$ & 17 \\
& Production \& Manufacturing & 13 & $\$ 37.5$ & 13 \\
& Maintenance \& Repair & 32 & $\$ 33.8$ & 30 \\
& Administrative \& Customer Service & 21 & $\$ 18.9$ & 11 \\
& Management \& Business & 19 & $\$ 55.6$ & 29 \\
& Sales & 12 & $\$ 34.4$ & 11 \\
& Other & 4 & $\$ 48.9$ & 5 \\
\hline
\end{tabular}

\section{FEW interconnections and impact of labor shortage on productivity}

In a general sense, the productivity of water or energy systems is a function of the productivity of each worker. The linkage between individual productivity and the productivity of the systems is blurred and seldom one to one. To gauge the individual's contribution to the system productivity, hourly wages of the selected occupations related to water and energy systems are used. In other words, the occupations with higher hourly wages contribute more to the productivity of the system. Table 11 shows that employment in energy and water systems are divided into six classes of occupations. The following equation calculates the share of each class of occupation in the total system productivity (Productivity Share):

Productivity Share $=\frac{\text { Occupation Share } \times \text { Hourly Wage }}{\sum_{i=1}^{n}(\text { Occupation Share } \times \text { Hourly Wage })_{i}}$

where $\mathrm{n}$ is the number of occupation classes, e.g., 6 for this study. The productivity share of $8 \%$ for Administrative \& Customer Service positions in the water system means that if we lose all occupations in this class (14\% of total water workforce), the system productivity reduction is projected to be about $8 \%$.

The FEW systems are interdependent and a sudden labor shortage in one system can trigger the failure of other systems and so on. Cascading failures are taken into consideration in this study to analyze the impact of labor shortage 


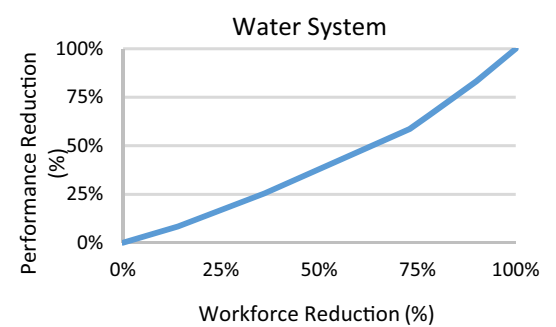

(a)

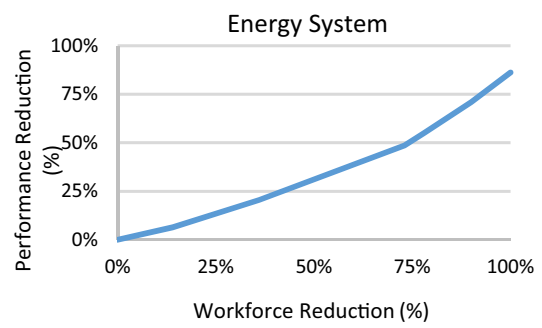

(b)

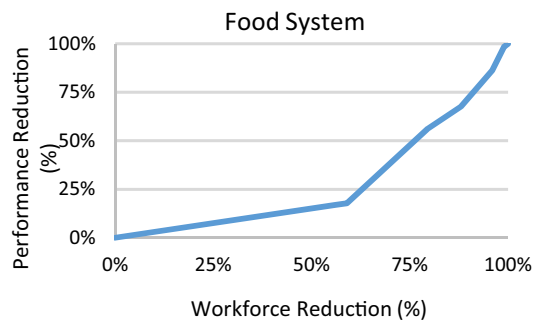

(c)

Fig. 4 Performance of water systems to labor shortage $\mathbf{a}$ direct impact on the water systems, $\mathbf{b}$ cascading effect on energy systems, and $\mathbf{c}$ cascading effect on food systems

on the system productivity. The impact of labor shortage in the water workforce (est. employment of 587,090) is shown in Figure $4 a$. For example, a $50 \%$ reduction in the water workforce would result in a $35 \%$ performance reduction. This production loss cascades through the components of the energy and food systems (e.g., thermoelectric power production) and continues until substantially all the components are compromised and/or the energy or food systems disconnect from the water source. The performance loss in the water system will be followed by a cascading failure of interconnected energy systems if no actions are taken to designate essential workers. Almost all major sources of electricity rely to some degree on water. As shown in Fig. 4b, the failure of the water system impairs the energy system. The direct consequences of water system disruptions on the food system are obvious. In addition, the performance reduction in the energy system followed by the water system disruptions can also impair food production. Therefore the performance of the food system decreases slowly at first, then increases more rapidly as workforce reduction increases (see Fig. 4c). Note that Fig. 4 is based on the assumption that only the water sector is facing a shortage of workers.
The impact of labor shortage in the energy workforce (est. employment of 2,359,244) is shown in Fig. 5a. For example, a $50 \%$ reduction in the energy workforce would result in a $38 \%$ performance reduction. Again, this production loss cascades through the components of the water and food systems (e.g., domestic supply), and the performance loss in the energy system will be followed by a cascading failure of interconnected water systems if no actions are taken to designate essential workers. The failure of the energy system impairs both the water and the food systems because pumps and other equipment do not work without electricity. Tables 2 and 3 show the electricity used for supplying water and food. The water or food groups that are less dependent upon energy are also more resilient to the energy system performance loss. This is why the performance reduction for the water and food systems increases slowly at first and then more rapidly as the energy supply disruption cascades through the components of more vulnerable water and food systems. As shown in Table 2, major water uses rely on energy to supply water. These cascading effects can be seen in Fig. $5 b$ and c. Note that all water uses are weighted equally.

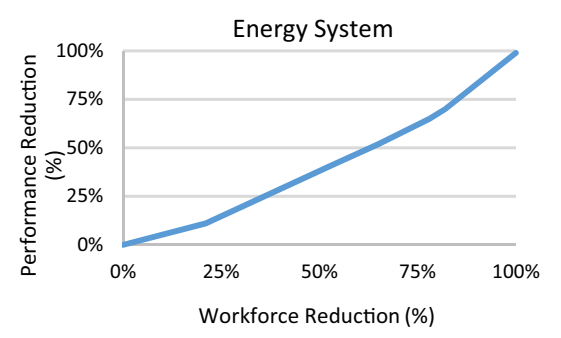

(a)

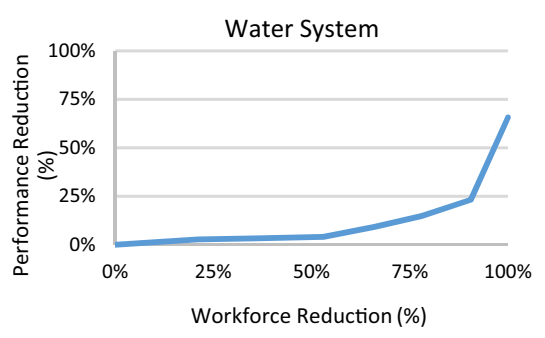

(b)

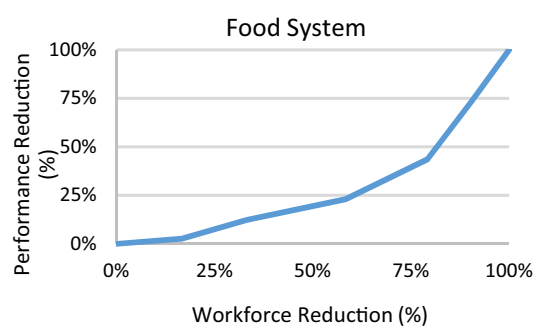

(c)

Fig. 5 Performance of energy systems to labor shortage: a direct impact on the energy systems, $\mathbf{b}$ cascading effect on water systems, and $\mathbf{c}$ cascading effect on food systems 
Fig. 6 Performance of food systems to labor shortage: a direct impact on the food systems and b cascading effect on energy systems

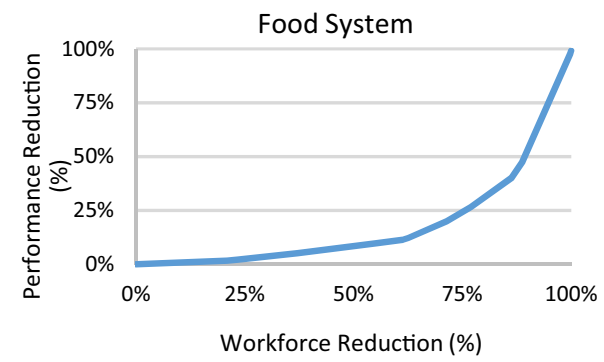

(a)

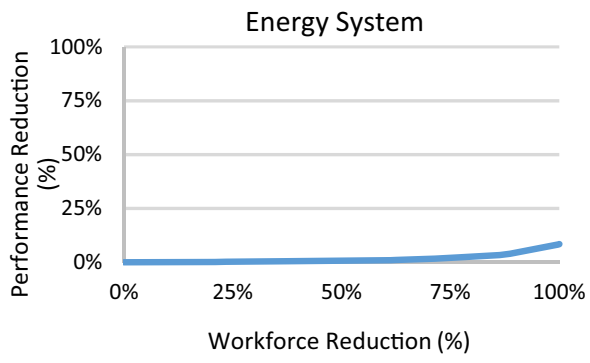

(b)
A food system needs to maintain its essential functions in the case of a disruptive event. This is possible by giving higher priority to subcategories that produce more with less labor (lower labor intensity and therefore labor dependency). Therefore, the rate of lost productivity due to a labor shortage increases slowly at first, then more rapidly as the number of workers decreases (see Fig. 6a). The performance of water systems is independent of food shock, however, disruptions on the food system would impact the production of ethanol and biofuel (see Fig. 6b).

\section{Example application of labor shortage and COVID-19}

The labor shortage in the FEW workforces caused by the COVID-19 pandemic is chosen to compare the proposed way of evaluating the resilience of FEW systems with the empirical data. The use case is illustrative and included only to demonstrate the application of the resilience metrics to measure the system performance and the role of adjustments and decisions on the overall increase in the system performance. We focus on workforce shortages directly impacted by the novel coronavirus disease, but other disruption and hazard types could be considered.

Figure 7 shows the U.S. workforce reduction caused by the pandemic and funding programs related to FEW systems to combat the pandemic. On 20 January 2020, the first known case of COVID-19 was confirmed in the USA On 31 January, the U.S. government declared a public health emergency, but it was not until 15 March that many businesses closed or reduced hours and, schools across the country were shut down ( $\mathrm{t}_{0}$ : start time of the disruptive event, March 15). Soon after, business establishments encouraged employees to work from home and all sports events and seasons were canceled. The U.S. government authorized the use of \$105 million to respond to coronavirus by March 15 and had spent $\$ 240$ million by March 22 and \$540 million by March 29 .

When the country saw its peak for unemployment filings during the week ending April 4, initial adjustments were taken to maintain continuity of operations of essential and critical infrastructure sectors. By April 19, the U.S. government provided $\$ 8.3$ billion in emergency funding for federal agencies to respond to the outbreak. The U.S. and local governments took advantage of technology and communication solutions to enforce social distancing policies until the end of April. By mid-May reports of new cases began to level off and most states began to open businesses. From midApril to mid-May, federal agencies tagged more than $\$ 76$ billion as being part of the $\$ 2.2$ trillion stimulus package, known as the Coronavirus Aid, Relief and Economic Security (CARES) Act.

The resilience metrics defined at the beginning of the study are used here to quantitatively measure the resilience
Fig. 7 Workforce reduction and funding spent due to the pandemic

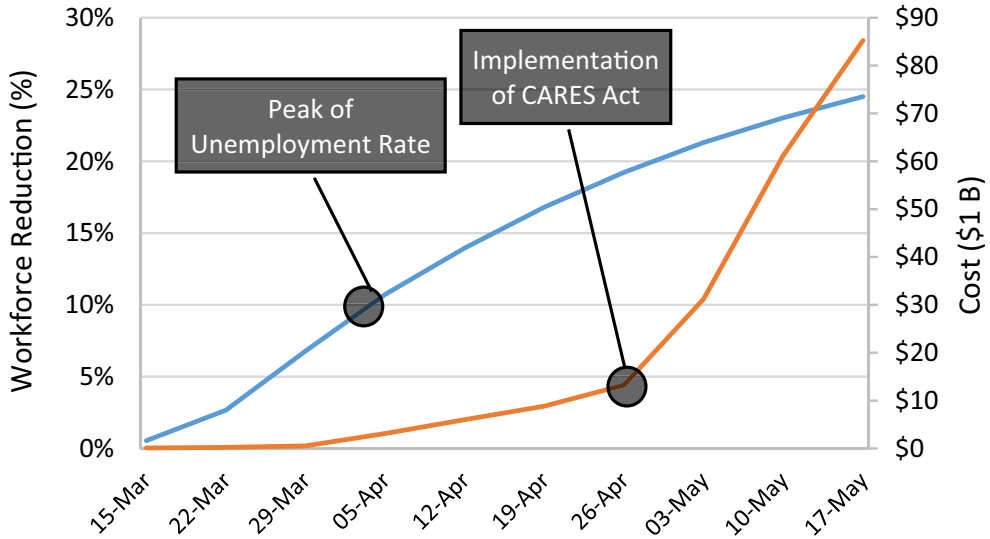




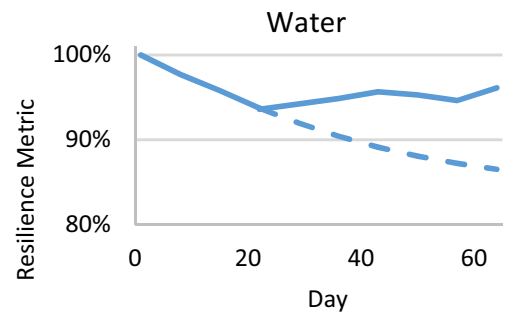

Performance with mitigation actions
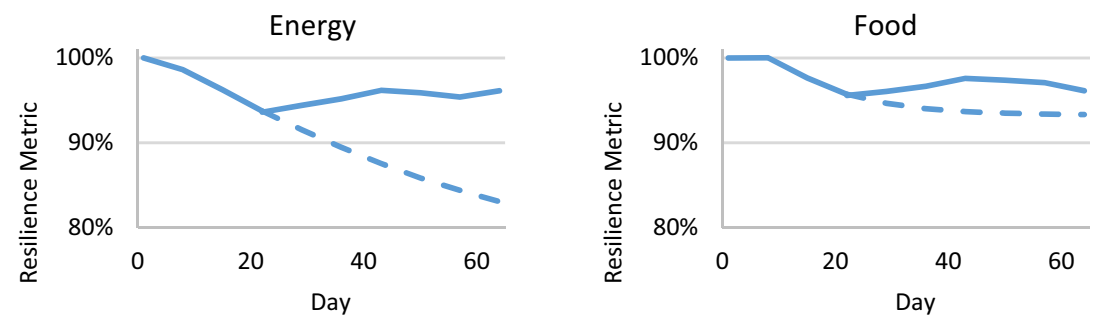

Performance projection without mitigation actions

Fig. 8 Resilience of FEW systems during the example application of COVID-19

of FEW systems. Figure 8 shows the impact of the workforce reduction caused by the pandemic on the FEW system performance. For simplicity, all subcategories of the FEW systems are weighted equally. The maximum amount of time post disaster for $t_{\text {slack }}$ is considered two months (until May 17). Also, the cost of full automation, $C_{\text {aut }}$, is considered $\$ 2.2$ trillion equal to the funds provided by the CARES Act.

The original stable performance level, $P_{0}$, is set at $100 \%$ equal to the FEW average consumptions per U.S. household (see Tables 2 and 3). The performance level post-disruption and before any recovery efforts (i.e., April 4 or day 21) follows the patterns shown in Figs. 4, 5, and 6 and falls at its lowest point, $P_{\mathrm{D}}$, during the pandemic. Up to this point, the integrated resilience metric represents the absorptive capacity resilience.

$R_{\text {abs }}=\frac{P_{\mathrm{D}}}{P_{0}} \gg R_{\text {water }}=\frac{93.7}{100}, R_{\text {energy }}=\frac{93.7}{100}, R_{\text {Food }}=\frac{95.7}{100}$

If no actions are taken to mitigate the impact of labor shortage, the performance continues declining for the rest of the pandemic period. This projection is shown with dashed lines in Figure 8. The adaptive capacity period begins on day 21 after implementing adjustments to maintain the operations of essential critical infrastructure sectors. The performance of the water and energy systems had improved more rapidly as essential workers represented nearly $85 \%$ of all water and energy workforce and due to a record drop in the transportation fuel demand. Such steady improvement is not observed for the food system because disruptions in some activities (e.g., harvesting activities and supply chains because of transportation problems) cannot be compensated. Day 50 is the time to complete initial adjustments, $t_{\mathrm{a}}$, and the time to final recovery is not yet to come.

\section{Conclusions}

The importance of enhancing the resilience of food, energy, and water systems have long been recognized. In this regard, researchers have established a set of metrics that adequately measure and evaluate the behavior of systems. Unfortunately, the state of practice is different. Although there are always improvements to be made to further develop these metrics (e.g., by adding new dimensions), it can be inferred that the broad scope and standardized form of these metrics are the reasons for their limited use. Lack of quantitative data to measure the system performance and not specific disruptive events are unexplored areas on which we should base our research. Comprehensive studies of FEW systems that specify the role of time, quantity, and quality of FEW uses on the system performance are rare in the published literature. For example, the authors could not find a single study where these dimensions are considered to assess the performance of the system over time. Time intervals are defined for each system to address this aspect of FEW system performance. Decisions or strategies that aim to enhance resilience in one domain (e.g., water system) can have consequences not only in the same domain but also in other ones (e.g.,, energy and food). These consequences are often substantial across time and space and not necessarily positive. The content presented in this study should prove useful to decision-makers and planners in the measurement of FEW system performance and their labor intensity and ultimately in the assessment of FEW resilience.

The major conclusion drawn from this research is that a labor shortage in the energy workforce has a relatively high impact on the FEW system performance. This can be explained by the fact that both water and food systems are largely dependent on energy sources and unlike food or water, electrical energy storage is significantly more expensive. Furthermore, the current food system is more resilient to a sudden labor shortage compared to the energy and water systems. Perhaps the variety of food groups and alternatives enables the food systems to better absorb the impacts of a 
sudden labor shortage, particularly when the reduction in the workforce or full-time workers is $50 \%$ or less.

The data collected and developed by both public and by private initiatives in this matter are crucial in assessing and comparing the effects of disruptive events on FEW systems. The lack of detailed data on FEW consumption patterns was a major challenge for our research to understand the effects of a labor shortage on the system performance. The overall challenge in the present study was the lack of segregated datasets and validated metrics. The study has contributed to the literature by providing a summarized format for the workforce directly involved in the production and governance of FEW systems. Supporting the collection of datasets that can be used for the FEW system assessments should be given priority. The lack of segregated employment data is more evident when measuring the labor intensity of FEW systems. It is important to know how many hours of work are involved in producing and distributing a pound of food, or a gallon of water, or a KWh of energy. Not only that, but it is also important to know what portion of these work hours are in support of production activities (e.g.,, administrative occupations), not to mention the quality of the workforce (e.g.,, education, experience, etc).

The data gathered and presented for measuring the labor intensity of FEW systems provided insightful findings and remarks for areas of future research. The results of this study contribute to professional planning practice by assessing the impact of labor shortage in the FEW workforces on the system performance. This will provide planners grounds on which to justify automating a process based on the labor content. The U.S. water system employs about 600,000 workers nationwide, making it the least labor-intensive sector compared to the energy and food sectors. The finding implies an easier path toward automation. The water supply for domestic and public uses needs nearly 70 times more workers to supply 1 gallon of water compared to other water uses. The use of water-efficient technologies, such as rainwater harvesting systems, offers the opportunity for greater productivity with less labor. The common uses of rainwater include irrigation and toilet flushing that can help to reduce the domestic water demands by $23 \%$ and ultimately improve the system's resilience. The interconnections between energy and water systems should not be neglected.

Energy systems require a significant amount of water for cooling systems. More than $80 \%$ of the electricity is generated by thermoelectric power plants. Energy generated by renewable sources (e.g.,, solar and wind) provides more resilient solutions. Even with the latest advancements in energy efficiency technologies, the energy sector still requires an enormous class of workers to administer, manage, and maintain energy system stability. The US food system employs about 2.6 million workers nationwide, making it one of the largest sectors in the USA and possibly the single largest employer in the world. This is surprising, at least when considering how much labor exertion goes with its production (e.g.,, 1.83 million pounds of wheat per worker). The COVID-19 pandemic exposed the food system weaknesses. Food production depends on water and thus increasingly subjected to water disruptions. On the other hand, the food system is highly dependent on energy not only to produce food, but also to process, transport, and store it. Investing in the resilience of food systems is, therefore, vital to withstand shocks or stresses that could lead to collapse.

Author contribution Both authors contributed to the study conception and design, and they read and approved the final manuscript.

Data availability Upon request, authors will provide relevant documentation or data to verify the validity of the results presented.

\section{Compliance with ethical standards}

Conflict of interest The authors declare that they have no conflict of interest.

\section{References}

AWWA (2019) Utility benchmarking: performance management for water and wastewater. American Water Works Association (AWWA), Denver, CO

Balducci PJ, Roop JM, Schienbein LA, DeSteese JG, Weimar MR (2002) Electric power interruption cost estimates for individual industries, sectors, and US economy. Pacific Northwest National Lab (PNNL), Richland, WA, USA, p 44

Barrett J, Yudken J (2020) 2020 U.S. Energy \& Employment report. Department of Energy, Washington, D.C., 250.

Blackwood J, Karan E, Asadi S, Mohammadpour A, Asgari S (2017) Stochastic optimization model for sustainable water treatment with minimal energy use. In: Proc., computing in civil engineering 2017, ASCE, pp 215-222. https://doi.org/10.1061/9780784480 847.027.

BLS (2019) Occupational Employment Statistics. https://www.bls.gov/ oes/current/oes_stru.htm Accessed 10 May 2020.

Bocchini P, Frangopol DM, Ummenhofer T, Zinke T (2014) Resilience and sustainability of civil infrastructure: toward a unified approach. J Infrastr Syst 20(2):04014004. https://doi.org/10.1061/ (ASCE)IS.1943-555X.0000177

Boyd CE, Tucker CS (2012) Pond aquaculture water quality management. Springer Science \& Business Media, Norwell, MA

Campbell RJ, Lowry S (2012) Weather-related power outages and electric system resiliency. Congressional Research Service, Washington DC, p 18

Cardot V, Le Roux Y, Jurjanz S (2008) Drinking behavior of lactating dairy cows and prediction of their water intake. J Dairy Sci 91(6):2257-2264. https://doi.org/10.3168/jds.2007-0204

Choi J, Deshmukh A, Hastak M (2019) Seven-layer classification of infrastructure to improve community resilience to disasters. J Infrastr Syst 25(2):04019012. https://doi.org/10.1061/(ASCE) IS.1943-555X.0000486 
DHS (2020) Critical infrastructure and resilience - current projects and programs. https://www.dhs.gov/science-and-technology/criticalinfrastructure-and-resilience. Accessed 20 May 2020

Dieter CA, Maupin MA, Caldwell RR, Harris MA, Ivahnenko TI, Lovelace JK, Barber NL, Linsey KS (2018) Estimated use of water in the United States in 2015. U.S. Geological Survey (USGS), Reston, VA, p 65

EIA (2017) Energy consumption estimates by sector. Monthly energy review, U.S. Energy Information Administration (EIA).

EIA (2020). How much gasoline does the United States consume? https://www.eia.gov/tools/faqs/faq.php?id=23\&t=10. Accessed 20 May 2020.

EPA (2010) Evaluation of energy conservation measures for wastewater treatment facilities. U.S. Environmental Protection Agency (EPA), Washington, DC

FMI (2017) U.S. Grocery Shoppers trends 2017. The Hartman Group, Inc., Arlington, VA, p 126.

Fox-Lent C, Bates ME, Linkov I (2015) A matrix approach to community resilience assessment: an illustrative case at Rockaway Peninsula. Environ Syst Decis 35(2):209-218. https://doi.org/10.1007/ s10669-015-9555-4

Francis R, Bekera B (2014) A metric and frameworks for resilience analysis of engineered and infrastructure systems. Reliab Eng Syst Saf 121:90-103. https://doi.org/10.1016/j.ress.2013.07.004

Fryar CD, Kruszan-Moran D, Gu Q, Ogden CL (2018) Mean body weight, weight, waist circumference, and body mass index among adults: United States, 1999-2000 through 2015-2016. Centers for Disease Control and Prevention, Hyattsville, MD, p 16

Ganin AA, Massaro E, Gutfraind A, Steen N, Keisler JM, Kott A, Mangoubi R, Linkov I (2016) Operational resilience: concepts, design and analysis. Sci Rep 6(1):1-12. https://doi.org/10.1038/ srep19540

Ghorbanian V, Karney B, Guo Y (2016) Pressure standards in water distribution systems: reflection on current practice with consideration of some unresolved issues. J Water Resourc Plan Manag 142(8):04016023. https://doi.org/10.1061/(ASCE)WR.19435452.0000665

Golan MS, Jernegan LH, Linkov I (2020) Trends and applications of resilience analytics in supply chain modeling: systematic literature review in the context of the COVID-19 pandemic. Environ Syst Decis 40:222-243. https://doi.org/10.1007/s10669-020-09777-w

Govindan R, Al-Ansari T (2019) Computational decision framework for enhancing resilience of the energy, water and food nexus in risky environments. Renew Sustain Energy Rev 112:653-668. https://doi.org/10.1016/j.rser.2019.06.015

Hashemi M, Jenkins GP, Jyoti R, Ozbafli A (2018) Evaluating the cost to industry of electricity outages. Energy Sources Part B 13(7):340-349. https://doi.org/10.1080/15567249.2018.1501122

Houpt KA (2018) Domestic animal behavior for veterinarians and animal scientists. John Wiley \& Sons, Hoboken, NJ

Hu Y, Li J, Holloway LE (2008) Towards modeling of resilience dynamics in manufacturing enterprises: literature review and problem formulation. In: Proc. IEEE international conference on automation science and engineering, IEEE, pp 279-284. https://doi.org/10.1109/COASE.2008.4626539.

Huzzey JM, von Keyserling MAG, Weary DM (2005) Changes in feeding, drinking, and standing behavior of dairy cows during the transition period. J Dairy Sci 88(7):2454-2461. https://doi. org/10.3168/jds.S0022-0302(05)72923-4

Hynes W, Trump B, Love P, Linkov I (2020) Bouncing forward: a resilience approach to dealing with COVID-19 and future systemic shocks. Environ Syst Decis 40:174-184. https://doi. org/10.1007/s10669-020-09776-x

IOM, and NRC (2015) A framework for assessing effects of the food system. MC Nesheim, M Oria, and PT Yih, (eds), National Academies Press, Washington, DC, p 430.
Karan E, Asadi S (2018) Quantitative modeling of interconnections associated with sustainable food, energy and water (FEW) systems. J Clean Product 200:86-99. https://doi.org/10.1016/j.jclep ro.2018.07.275

Karan E, Asadi S, Mohtar R, Baawain M (2018) Towards the optimization of sustainable food-energy-water systems: a stochastic approach. J Clean Product 171:662-674. https://doi. org/10.1016/j.jclepro.2017.10.051

Kebede T, Haji J, Legesse B, Mammo G (2016) Econometric analysis of rural households' resilience to food insecurity in West Shoa, Ethiopia. J Food Secur 4(3):58-67

Kennedy G, Ballard T, Dop MC (2011) Guidelines for measuring household and individual dietary diversity. Food and Agriculture Organization (FAO) of the United Nations.

Kenner B, Kramer J (2019) Fruit and tree nut yearbook tables. Economic Research Service USDA edn

Küfeoğlu S, Lehtonen M (2015) Interruption costs of service sector electricity customers, a hybrid approach. Int J Electr Power Energy Syst 64:588-595. https://doi.org/10.1016/j.ijepe s.2014.07.046

Kurth M, Kozlowski W, Ganin A, Mersky A, Leung B, Dykes J, Kitsak M, Linkov I (2020) Lack of resilience in transportation networks: Economic implications. Transp Res Part D 86:102419. https://doi.org/10.1016/j.trd.2020.102419

Kwasinski A (2016) Quantitative model and metrics of electrical grids' resilience evaluated at a power distribution level. Energies 9(2):93. https://doi.org/10.3390/en9020093

LaCommare KH, Eto JH (2006) Cost of power interruptions to electricity consumers in the United States (US). Energy 31(12):1845-1855. https://doi.org/10.1016/j.energ y.2006.02.008

Ladha-Sabur A, Bakalis S, Fryer PJ, Lopez-Quiroga E (2019) Mapping energy consumption in food manufacturing. Trends Food Sci Technol 86:270-280. https://doi.org/10.1016/j.tifs.2019.02.034

Lawton L, Sullivan M, Van Liere K, Katz A, Eto J (2003) A framework and review of customer outage costs: integration and analysis of electric utility outage cost surveys. Lawrence Berkeley National Lab. (LBNL), Berkeley, CA (United States), Berkeley, CA

Lemer AC (1996) Infrastructure obsolescence and design service life. J Infrastr Syst 2(4):153-161. https://doi.org/10.1061/ (ASCE)1076-0342(1996)2:4(153)

Liddel M, Yencho M (2020) Fisheries of the United States. U.S. Department of Commerce, Silver Spring, MD, p 169

Lizarraga SA (2013) The economic consequences of water utility disruptions. $\mathrm{PhD}$, University of Missouri Columbia, Missouri

MacDonald R, Reitmeier C (2017) Understanding food systems: agriculture, food science, and nutrition in the United States. Academic Press, Cambridge, MA

Martland CD (2012) Toward more sustainable infrastructure. Wiley, Hoboken, NJ

Mekonnen MM, Hoekstra AY (2010) The green, blue and grey water footprint of farm animals and animal products. UNESCO-IHE Institute for water Education Delft, Enschede

Mumby PJ, Chollett I, Bozec Y-M, Wolff NH (2014) Ecological resilience, robustness and vulnerability: how do these concepts benefit ecosystem management? Curr Opin Environ Sustain 7:22-27. https://doi.org/10.1016/j.cosust.2013.11.021

Nanab C, Sansavinibc G, Krögerc W, Heinimannac HR (2014) A quantitative method for assessing the resilience of infrastructure systems. In: Proc., probabilistic safety assessment \& management, IAPSAM, pp 359-370

Ouyang M, Dueñas-Osorio L, Min X (2012) A three-stage resilience analysis framework for urban infrastructure systems. Struct Saf 36:23-31. https://doi.org/10.1016/j.strusafe.2011.12.004

Ouyang M, Fang Y (2017) A mathematical framework to optimize critical infrastructure resilience against intentional attacks. 
Comput Aided Civil Infrastr Eng 32(11):909-929. https://doi. org $/ 10.1111 /$ mice. 12252

Ouyang M, Wang Z (2015) Resilience assessment of interdependent infrastructure systems: with a focus on joint restoration modeling and analysis. Reliab Eng Syst Saf 141:74-82. https://doi. org/10.1016/j.ress.2015.03.011

Pant R, Zorn C, Thacker S, Hall JW (2018) Systemic resilience metrics for interdependent infrastructure networks. In: 6th International symposium on reliability engineering and risk management (6ISRERM), Singapore, pp 37-42

Panteli M, Mancarella P, Trakas DN, Kyriakides E, Hatziargyriou ND (2017) Metrics and quantification of operational and infrastructure resilience in power systems. IEEE Trans Power Syst 32(6):4732-4742. https://doi.org/10.1109/TPWRS.2017.26641 41

Parr B, Minor K, Bond J (2018) Vegetable and pulses yearbook data. Economic Research Service USDA, edn

Reichl J, Schmidthaler M, Schneider F (2013) Power outage cost evaluation: reasoning, methods and an application. J Sci Res Rep 2(1):249-276. https://doi.org/10.9734/JSRR/2013/3167

Schade J (2006) The complete encyclopedia of medicine \& health. Foreign Media Group, Yardville, NJ

Schlör H, Venghaus S, Hake J-F (2018) The FEW-Nexus city indexMeasuring urban resilience. Appl Energy 210:382-392. https:// doi.org/10.1016/j.apenergy.2017.02.026

Scott CA, Kurian M, Wescoat JL (2015) The water-energy-food nexus: enhancing adaptive capacity to complex global challenges. In: Governing the nexus. Springer, New York, pp 15-38

Segneanu A, Grozescu I, Cepan C, Velciov S (2018) Significance of food quality on human health. Appl Food Sci J 2(2):17

USDA (2015) 2015-2020 dietary guidelines for Americans, 8th edn. US Department of Agriculture (USDA), $\mathrm{p} 122$

USDA (2018) Employment in agriculture, food, and related industries. https://www.ers.usda.gov/data-products/chart-gallery/galle ry/chart-detail/?chartId=58282. Accessed 10 May 2020.
Vogt K, Patel-Weynand T, Shelton M, Vogt DJ, Gordon JC, Mukumoto C, Suntana AS, Roads PA (2012) Sustainability unpacked: food, energy and water for resilient environments and societies. Routledge, London

Vugrin E, Castillo A, Silva-Monroy C (2017) Resilience metrics for the electric power system: a performance-based approach. Report: SAND2017-1493, Sandia National Laboratories, Albuquerque, New Mexico, p 49

Vugrin ED, Warren DE, Ehlen MA (2011) A resilience assessment framework for infrastructure and economic systems: quantitative and qualitative resilience analysis of petrochemical supply chains to a hurricane. Process Saf Prog 30(3):280-290. https:// doi.org/10.1002/prs.10437

Vugrin ED, Warren DE, Ehlen MA, Camphouse RC (2010) A framework for assessing the resilience of infrastructure and economic systems. In: Sustainable and resilient critical infrastructure systems. Springer, Berlin, pp 77-116

Watson J-P, Guttromson R, Silva-Monroy C, Jeffers R, Jones K, Ellison J, Rath C, Gearhart J, Jones D, Corbet T (2015) Conceptual framework for developing resilience metrics for the electricity oil and gas sectors in the United States. Sandia national laboratories, albuquerque, nm (united states), tech. rep, Sandia National Laboratories, Albuquerque, New Mexico, p 104

Zhuang B, Lansey K, Kang D (2013) Resilience/availability analysis of municipal water distribution system incorporating adaptive pump operation. J Hydraul Eng 139(5):527-537. https://doi. org/10.1061/(ASCE)HY.1943-7900.0000676

Zimmerman R, Zhu Q, Dimitri C (2016) Promoting resilience for food, energy, and water interdependencies. J Environ Stud Sci 6(1):50 61. https://doi.org/10.1007/s13412-016-0362-0 